\title{
Squaring up to reality
}

\author{
MARTIN PARRY, JEAN PALUTIKOF, CLAIR HANSON AND JASON LOWE
}

\section{Both emissions reduction and adaptation will need to be much stronger than currently planned if dangerous global impacts of climate change are to be avoided. June's UN talks in Bonn and July's G8 summit present opportunities for world leaders to face this challenge.}

W e are now probably witnessing the first genuinely global effects of greenhouse gas warming. The steep increases in food prices around the world are the result of rising costs and demand aggravated by drought in food-producing regions - in the case of Australia, probably due in part to global warming - and by a poorly conceived experiment in climate policy that has converted cropland to biofuel plantations. This should serve as a wake-up call: impacts of climate change can surprise us, especially when they act in combination with other pressures.

We must use this as an opportunity to clarify climate policies, in particular the amount of emissions reductions needed globally to avoid dangerous climate change, generally defined as more than a $2{ }^{\circ} \mathrm{C}$ increase on pre-industrial temperatures ${ }^{1}$. Two forthcoming meetings - the UN climate change talks to take place in June in Bonn, Germany, and July's G8 summit in Hokkaido, Japan - provide yet another chance for world leaders to boldly declare their commitment to dramatically reducing greenhouse gases. Both will represent important milestones ${ }^{2}$ in the lead-up to the UN climate change conference in Copenhagen in 2009, where an international deal will be agreed that will tackle carbon emissions beyond 2012 after the present pledges in the Kyoto Protocol run out.

Last year's G8 summit in

Heiligendamm, Germany, resulted in a joint statement from international delegations that acknowledged a preference for global greenhouse gas emissions to be cut to 50 per cent below 1990 levels by 2050 , though no mandatory target was set ${ }^{3}$. More recently, at the UN climate change conference in Bali last December, where a 'road map' to Copenhagen was laid out, over 200 members of the climate science community, including many involved in

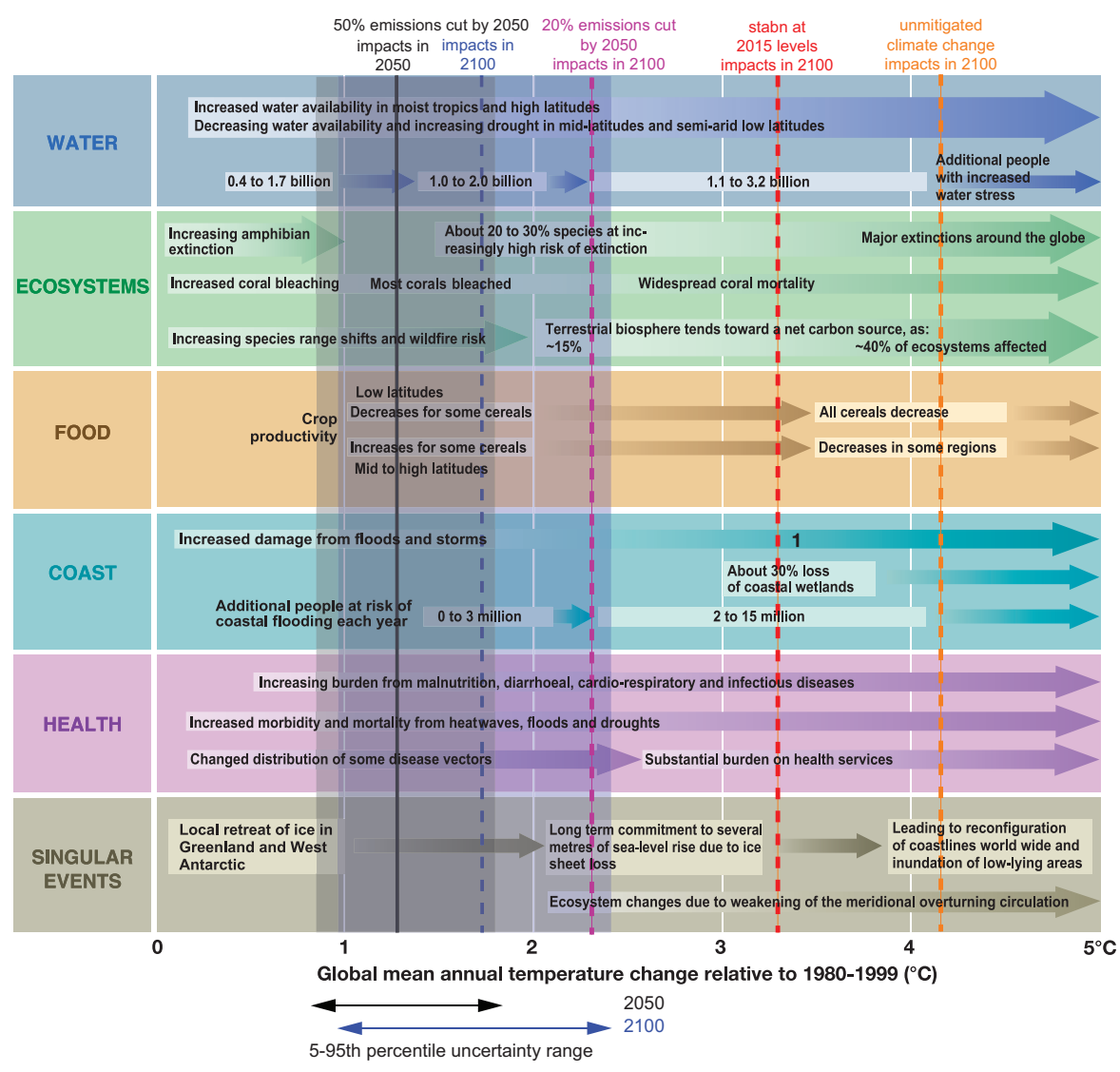

Figure 1 Selected global impacts from warming associated with various reductions in global greenhouse gas emissions. Vertical lines indicate likely impacts of the median warming expected to result from indicated emissions scenarios (percentage cuts are from 1990 levels); shaded columns show 5 to 95 per cent uncertainty ranges for impacts of a 50 per cent cut. Adapted from ref. 6 .

the Intergovernmental Panel on Climate Change (IPCC), issued a declaration calling for global emissions to be cut to at least the mid-century 50 per cent target ${ }^{4}$.

Other stakeholders, such as Germany, have called for a bolder emissions target, in the region of 80 per cent below 1990 levels by 2050, arguing that this is necessary to avoid serious impacts in the most vulnerable parts of the world 5 . New evidence presented here supports this case.

Extraordinarily, emissions targets have generally been based only on anecdotal rather than systematic information about potential damage - because the latest IPCC report was the first to clearly delineate how impacts might increase along with temperatures. The 
lack of a clear measure of pay-offs is one reason why targets have not been easy to agree upon.

\section{CUTS AND CONSEQUENCES}

This can now be partly rectified. The 2007 IPCC assessment report offers the first tables of expected impacts scaled against climate change ${ }^{6}$. Figures 1 and 2 plot against these impacts the probable outcomes of reducing emissions by specific amounts and could thus be used as a rubric to inform policy decisions.

The figures speak for themselves, and they are not at all encouraging. First, a 50 per cent reduction of global emissions below 1990 levels by 2050, widely considered to be the most stringent achievable target, will not avoid major global impacts. At this level of emissions, there is a good chance in 2050 of avoiding a temperature rise of $2{ }^{\circ} \mathrm{C}$ above pre-industrial levels (equivalent to $1.6^{\circ} \mathrm{C}$ above 1990 global temperatures; see Fig. 1), which is the European Union's target. That misleadingly appears to be a satisfactory outcome, but it omits that, even with further reductions after 2050, we would be locked into a warming trend until at least 2100 owing to inertia in the climate system, and damages would therefore accumulate beyond mid-century. By 2100 there would be a greater than 50 per cent chance of exceeding the $2{ }^{\circ} \mathrm{C}$ target - assuming the same percentage reductions in emissions continue annually from 2050 through to 2100 .

\section{We have lost ten years talking about climate change but} not acting on it. A curious optimism - the belief that we can find a way to fully avoid all the serious threats [of climate change - pervades the political arenas of the G8 summit and UN climate meetings. This is false optimism, and it is obscuring reality.

Even if 2100 seems like a far-off destination from a policy perspective, a 50 per cent emissions cut also commits the world to substantial harm in the shorter term: there is an even chance of around 1 billion people being short of water by 2050 , a number that rises

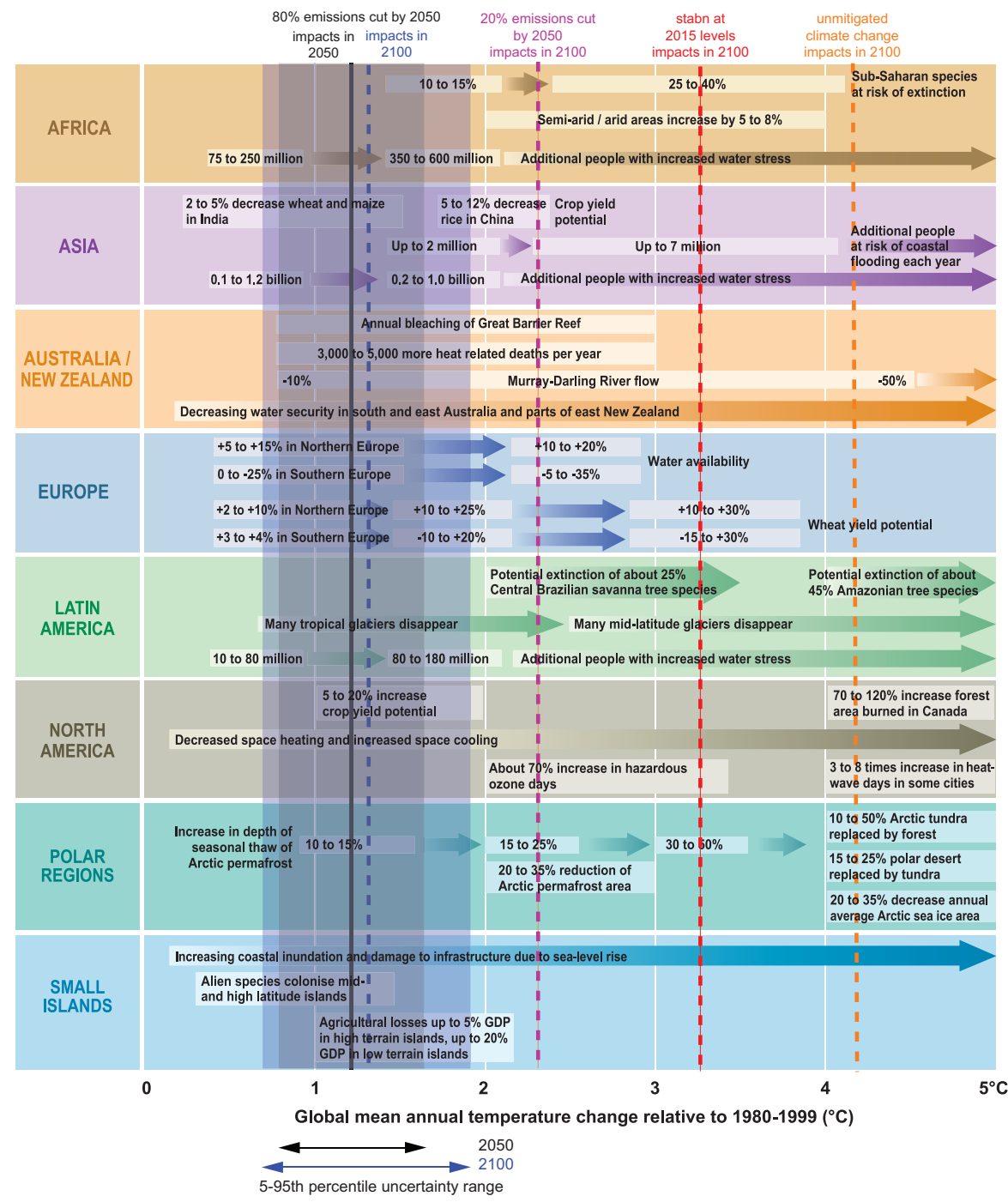

Figure 2 Selected regional impacts from warming associated with various reductions in global greenhouse gas emissions. Impacts are indicated as in Fig. 1, except uncertainty range is for an 80 per cent cut. Adapted from ref. 6 .

as high as 2 billion by 2100 (Fig. 1). Limiting impacts to acceptable levels by mid-century and beyond would require an 80 per cent cut in global emissions by 2050. This cut would stabilize atmospheric greenhouse gas levels at 400-470 parts per million of carbon dioxide equivalents instead of the 450-550 parts per million that would be reached if we cut emissions by 50 per cent from 1990 levels. Figure 2 shows that, under this policy, there is almost no chance of exceeding $2{ }^{\circ} \mathrm{C}$ in 2050 and only a small likelihood in 2100. Compared with 50 per cent, an 80 per cent target would substantially reduce the harm caused by climate change: for example, it would halve the population put at risk of water stress and flooding.

\section{ADAPTATION UNAVOIDABLE}

However, even with an 80 per cent emissions cut, damages will be large: any impact that occurs below a temperature rise of $1{ }^{\circ} \mathrm{C}$ (Figs. 1 and 2) is likely to be unavoidable, even under the most stringent mitigative action. Residual damage will be great unless we invest in adaptation now. Much of the damage could be avoided by adaptation, but again, this would require a much larger effort than is currently planned.

Ten years ago one of the authors, Martin Parry, proposed that adaptation would be unavoidable 7 . This view was criticized as 'defeatist', but the data now clearly support it. Much more importantly, we now have the knowledge to make a more informed choice regarding the optimal balance between mitigation and 
adaptation, and we know that immediate investment in adaptation will be essential to buffer the worst impacts. This does not mean that mitigation can be delayed, but quite the opposite: the longer we delay mitigation, the more likely it is that global change will exceed our capacity to adapt.

\section{FALSE OPTIMISM}

We have lost ten years talking about climate change but not acting on it. Meanwhile, evidence from the IPCC indicates that the problem is bigger than we thought. A curious optimism - the belief that we can find a way to fully avoid all the serious threats illustrated above - pervades the political arenas of the G8 summit and UN climate meetings. This is false optimism, and it is obscuring reality. The sooner we recognize this delusion, confront the challenge and implement both stringent emissions cuts and major adaptation efforts, the less will be the damage that we and our children will have to live with.

\section{Published online: 29 May 2008}

\section{doi:10.1038/climate.2008.50}

\section{References}

1. Avoiding Dangerous Climate Change: International Symposium on the Stabilization of Greenhouse Gas Concentrations (Report of the International Scientific Steering Committee, Hadley Centre, Met Office, Exeter, UK, 2005); http://www.stabilisation2005. com/Steering_Commitee_Report.pdf

2. Walker, G. \& King, D. The Hot Topic: How to Tackle Global Warming and Still Keep the Lights On (Bloomsbury New York, 2008).

3. BBC News 7 June 2007 ; http://news.bbc.co.uk/1/hi/world/ europe/6731045.stm
4. Towie, N. Nature News 6 December 2007; http://wwwnature. com/news/2007/071206/full/news.2007.361.html

5. Lenton, T. \& Schellnhuber, J. Nature Reports Climate Change 1, 97-98 (2007).

6. Parry M. L. et al. in Climate Change 2007: Impacts, Adaptation and Vulnerability. Contribution of Working Group II to the Fourth Assessment Report of the IPCC

Technical Summary, 23-78 (Cambridge University Press, Cambridge, UK, 2007).

7. Parry, M. L., Arnell, N. W., Hulme, M., Nicholls, R. \& Livermore, M. T. J. Nature 395, 741 (1998).

Martin Parry, Jean Palutikof and Clair Hanson led the impacts assessment for the IPCC, as co-chair, head and deputy head, respectively, of the Technical Support Unit of Working Group II. The views expressed here are their own. Jason Lowe is a climate scientist in the UK Met Office and provided the underlying scenarios. e-mail:martin@mlparry.com

\section{naturenews}

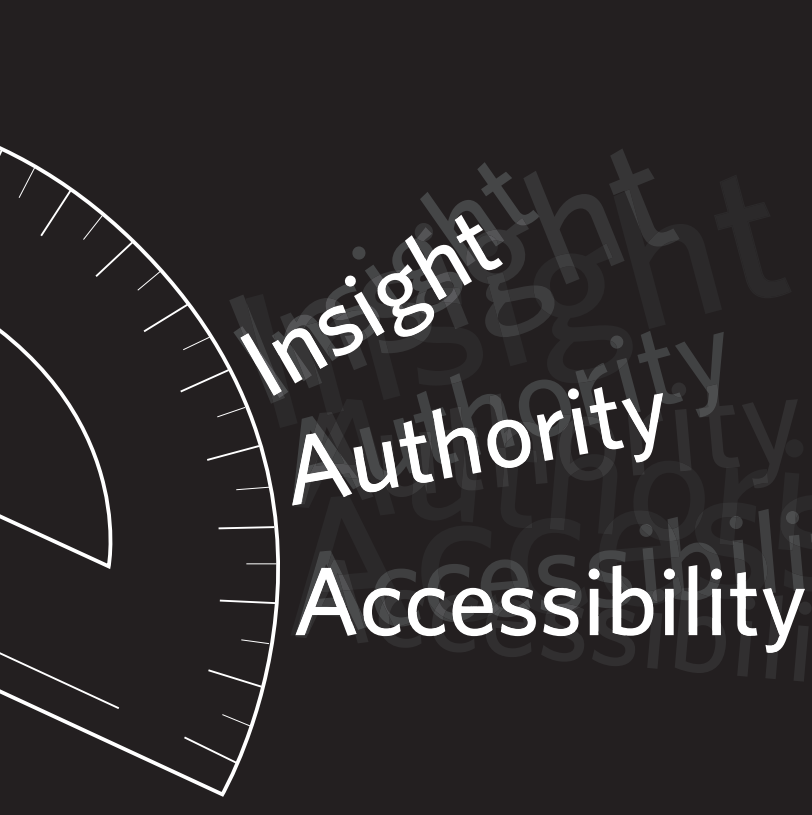

\section{Science news from a different angle}

\begin{abstract}
From daily science updates to investigative journalism, from community commentary to editorial opinions, Nature brings you the most in-depth science news coverage online.
\end{abstract}

Visit our new blog, The Great Beyond, for a comprehensive round-up and expert discussion of today's science news from around the world.

Subscribe to Nature and receive full access to Nature News as well as weekly issues of the most influential scientific journal in the world, in print and online. 